\title{
Study on Chinese Medical Safeguard Domain Public Question under the Background of the New Medical Reform
}

\author{
Wu Qi ${ }^{1} \& \mathrm{Yu} \mathrm{Kai}^{2}$ \\ ${ }^{1}$ School of Management, Shanghai University of Engineering Science, Shanghai, China, \\ ${ }^{2}$ Social Science Institute, Shanghai University of Engineering Science, Shanghai, China \\ Correspondence: Wu Qi, Room 404, No. 56, Wenhui Road, Songjiang District, Shanghai, China. Tel: \\ 86-151-2100-0384. E-mail: wuqimm1990@163.com
}

Received: November 2, 2013 Accepted: November 16, 2013 Online Published: November 29, 2013

doi:10.5430/sass.v1n1p32 URL: http://dx.doi.org/10.5430/sass.v1n1p32

\begin{abstract}
The Medical Security public is one of qualities of The Medical Security, involves social resources, influence for the common interests of members of society. Under the background of the New Medical Reform, Medical security is gradual paid more attention to the public health service than market's, is gradual realized the necessary for public health services. But for the moderate problem of Medical security public has still not been effectively solved. Based on the New Medical Reform as an opportunity, this paper analyses the change of medical insurance policy in our country, and then to define the commonality of health care, trying to balance the efficiency of marketization of medical service and fairness of the relationship between the public health service, further elaborates the deep-seated causes of loss of publicity, and puts forward the corresponding countermeasures and Suggestions, for better improvement for the Medical Security.
\end{abstract}

Keywords: medical security, public property, the lack of public character, public management

\section{Introduction}

Medical security is a matter of social economic development level; the major problem is the people's livelihood. In China, the medical insurance policy public is actually a conflict game, which is the relationship of efficiency and fairness and the pursuit of public interests and private interests. Review of China's reform of the medical security for decades to now, we will find the formulation and implementation of the medical domain policy is not blindly pursue and maintain the public interest. In 1992, with "some opinions" on deepening health reform, breaking the formed by the founding of egalitarianism, with only focus on equity of medical security system, and pay attention to the efficiency of the medical insurance market reform. However, the process of introducing market mechanism reform in the medical field, we found that the medical security obviously shows the characteristics of market value, neglect management and then the value orientation of the medical security is from its public interest, namely medical security serious loss of public property. This is why our medical insurance market reform as a whole is a failure. In order to make the medical security for public interest regression, and solve a series of social problems which are caused that the medical insurance market excessive pursuit of efficiency, in 2009 officially released the "CPC Central Committee and the State Council on deepening the reform of the medical and health system". This reform to strengthen the government's responsibility in medical insurance system, medical security in pay attention to efficiency and fair also return to its public character, also suggests that our country attaches importance to public interests in medical and health field of public policy. However, in the policy implementation is another picture, and after several years of practice, many in the medical safeguard social problems still not been effectively solved. Especially how to deal with the field of medical care medical insurance relationship between public and efficiency and find the best game of them. However, there is still lack of public property on the game of public and efficiency in the field of medical care.

\section{The Public Principle of Healthcare}

Public health care is mainly reflected the public as the main body, the public security target, security of public values, namely the state responsibility, provide health care services to meet all the social medical needs, thereby maintaining the fair's basic medical and health service resource equality. In the field of medical care, to ensure the healthy 
operation of the medical security system, balance the relationship between fairness and efficiency, the public interest and private interest, the public principle of health care were summarized as follows:

\subsection{To Ensure that the Public Body of Medical Security}

Medical security is an activity involving the public interests of the management activities. In order to guarantee the realization of public interests, the main responsibility of medical security must be the state and government. The country through the legal framework provides medical insurance system legislation plan, organization and implementation of the medical insurance plan.

Government as the main responsibilities of health care, in the new medical reform conditions, its function mainly includes two aspects. On the one hand, it must ensure that all citizens can enjoy basic medical service in an appropriate way. On the other hang it should appropriate management of medical insurance, guarantee the medical insurance system specification and orderly.

\subsection{To Ensure Public Health Care Goals}

The medical security system service and produce are quasi public produce and service features strong externalities. To promote the public interest, improve the overall interests of society, health care goals must guarantee its publicity, ensure the reproduction of labor, social stability and economic growth. Public principle of medical security objectives includes two aspects. First of all, the public medical insurance system must ensure the fairness, universality, to meet the public medical needs; secondly, the medical security objectives of the public must conform to the level of social development. Although the provisions of medical security in various regions of different, but must conform to the public interests. As a result of local residents disposable income, price and so different, the health care financing and payment to the corresponding change.

\subsection{To Ensure Public Health Security Values}

Medical insurance as a public management, it must ensure that the public value of medical security. The public values reflected in the equality, equity, ethics and responsibility. Medical security system is not running in the pursuit of personal efficiency and benefits maximization as the value orientation, need to uphold the value orientation of social justice for the welfare of the public. But the medical guarantee of equality and fairness is not absolute, should seek the relative fairness and equality, in health care between different groups, between different regions, different levels of economic development between adhering to the relative fair.

\section{Loss of Public Health Security}

\subsection{The Lack of the Public of Medical Security Body}

And since the new medical reform, medical service gradually by the market to return to public welfare, the government and the country has gradually increased in the position, its importance is gradually increasing. The government function is policy, raise funds and social control in the field of medical care. While the government as the main body of the medical security system, a fundamental role is failure problem of healthcare market, but the government failure exists. The government is not pure "social person", but also "economic man" and "rational people", have a tendency to pursue the interests of the sector, unconstrained by property and profit, easily lead to the unreasonable allocation of resources, also means that the deviation of government public. Especially after the reform of medical system, the government greater powers of medical security, possibility of low efficiency problem becomes stronger. The government's self-interest may harm the public interest in medical field. For medical service providers, use inferior patients and medical insurance fund in information, access to their own interests through the open prescription, excess examination means, resulting in health care resource use and waste land. Public hospitals as the main medical service system in China, because of the limited funds, public hospitals can not achieve to generate income for purpose, for its own interests, regardless of public health security, and "curing the sickness to save the patient" eventually becomes the interests of the carrier. Although, in 2009 the Ministry of Health issued a circular, emphasizing the prohibited all kinds and levels of public hospital issued revenue index to the Department, is strictly prohibited to be directly linked to the income of medical personnel with the Department of economic income. The same year, issued a "reform of medicine and medical services price formation mechanism of opinions", but the results are unsatisfactory. Hospitals and doctors still pay attention to more personal interests, rather than the interests of the public, resulting in the loss of public healthcare.

\subsection{The Lack of Public Character of Allocation of Medical Resources}

Since the new medical reform, public health resource allocation still fails to get a good solution, such as unreasonable allocation of medical resources supply, and reduce the serious which impact the realization of people's 
convenience and low cost medical needs. The first public hospital institutions distribution imbalance between urban and rural areas, public hospital distribution gap is very serious, the distribution of public hospitals in the big city is more reasonable, the more comprehensive medical institutions, but in small city and rural is unable to meet the needs of the people. Layout imbalance of public hospital directly affects the accessibility of public health resources, affect the overall social welfare level. Secondly, the medical and health disparities, our goal is to establish a multilevel medical security system based on low level, wide coverage; however, the health condition of public health has also big difference in real life. Living in a big city residents can enjoy better medical services and medical and health conditions, but in poor areas, and often enjoy only poor health conditions. According to the 2010 "China Health Statistical Yearbook" relevant data, by the end of 2009, urban and rural per thousand population total hospital beds 7.25 , urban per thousand population health agency 6.23 beds per thousand populations, township health hospital beds 1.02 , the city is 6.1 times of the Township. Medical service process and results of unfair is come from the difference between of the region of medical level. The distribution of medical resources unfair react the medical security of public loss too.

\subsection{The Lack of Public Value of Medical Security}

Modern administrative system faces the biggest challenge is to public administration "public spirit" neglect. There are also in the field of medical care, mainly displays in two aspects. One is the government in the management of non - public tendency. Problems solving are often tried to find an unanimity rule which suit for both private and public sector in the medical field. Two is the deviation of basic value, the efficiency as the ultimate goal. Lack of awareness of the public concept, caused by various departments between mutual shirk responsibility, mutual deception between the main medical securitize.

\section{The Reasons of Medical Security Public Loss}

\subsection{The Defect of the Basic Medical Insurance System}

Retrospect of reform of medical security system of our country can be found is a form the emphasis on fairness to respect the market efficiency, and then to the development of public welfare regression. Through the process before the market reform, it is complicate between the market and non market in health care, fairness and efficiency. At the same time, two structures in urban and rural areas is not equal, resulting in between urban and rural medical security is not fair which mainly shows in two aspects. One is the fiscal subsidy policy is not uniform between urban and rural areas. The second is the design of urban and rural system is not unified, the medical insurance system for urban residents in the design, providing multilevel, choosing the security system for residents. Urban residents medical insurance has a series of supporting system, different levels through different ways in solving the medical problems, such as residents pay medical insurance costs beyond the provision of basic medical security, and then can be added by commercial insurance, social groups, charity and so. The rural medical security system is lack of corresponding system. When farmers unable to pay medical insurance subsidies which is deducted charges outside, and often choose to give up treatment, resulted in farmers participating enthusiasm is not high. In the field of medical care, if it can be not broken between urban and rural equality system, and cannot co-ordinate arrangements between urban and rural medical and health service, true justice will not be able to achieve, don't talk about public health care the more.

\subsection{The Scattered Medical Insurance Management}

At present, China's medical security system mainly includes urban basic medical insurance, urban resident basic medical insurance, new rural cooperative medical insurance. They are managed separately by the Ministry of human resources and social security and the Ministry of health, which makes different medical security system provides content is not the same as. In the scattered management system, on the one hand, lack of planning and coordination, increase the management cost. In the decentralized management, information sharing barriers between departments, between the system obstacles, greatly increase the cost of management. On the other hand, the scattered management increases the medical security transfer relations difficulty. Medical insurance transfer of relation for identity transformation, changing of occupation, different departments for their maximizing interests select the insured personnel, makes the public medicate destruction.

\subsection{Unreasonable of Distribution Structure and Proportion of Financial Investment}

Because of fiscal spending on health care is not reasonable, prompt medical institutions have to gain benefit from the market, thereby increasing income. While the market mechanism play an important role in the process of medical institutions, even the medical institutions show excessively market, so as to gradually reduce the public of health security. Financial allocation structure unreasonable makes medical resources between regions, between the various departments of the configuration unreasonable. In some areas, departments of excessive medical resources, and some 
other health resources is serious shortage. The urban population accounted for about $30 \%$ of the total population, and urban population enjoys the medical health resources is the total resources of the $80 \%$, then compared for $70 \%$ of the total population of rural residents to enjoy the health resources is only $20 \%$ of the total resources. In recent years, china's urban medical insurance system has been increased significantly, and invested large amounts of funds and manpower. But at the same time, it has ignored about the establishment of rural health institutions and medical and health facilities. Many residents in remote areas difficult and expensive problems are not solving, medical equipment. The medical treatment of rural residents is more backward, caused the gap between urban and rural health to enjoy the health resources is more and more bigly, Which severely damage the public health security.

\section{Suggestions and Countermeasures}

\subsection{To Accelerate the Improvement of the Basic Medical Insurance System}

By summarizing the practice experience in the medical security system, in the basis of balancing the interests of the parties, solving the relationship of public and efficiency, and broking the urban-rural gap as soon as possible to improve the medical security system, make up the public caused by defects in the system. Through the gap between urban and rural areas to break in the medical security, to establish a basic medical insurance system for all, which exert mutual aid in all the residents, risk-sharing role in all patients, reduce the economic risk, all residents can afford disease. Construction steps as shown in Figure 1 of medical security system. At the same time, unified management of the medical security, reduce the cost of health care. To realize the true meaning of justice, reflect that the public should health care field. The government is the main responsibility for health care and other public goods, medical support in the field of public policy should adhere to the public benefit as the value orientation, in order to achieve social fairness policy goals, ensuring all citizens equal access to medical care resources. The public policy formulation system ensure social member's right to know, right to participate, to improve the democratic, scientific decision-making, makes full use of experts and scholars and think tanks to improve scientific decision, to protect the public nature of public policy.

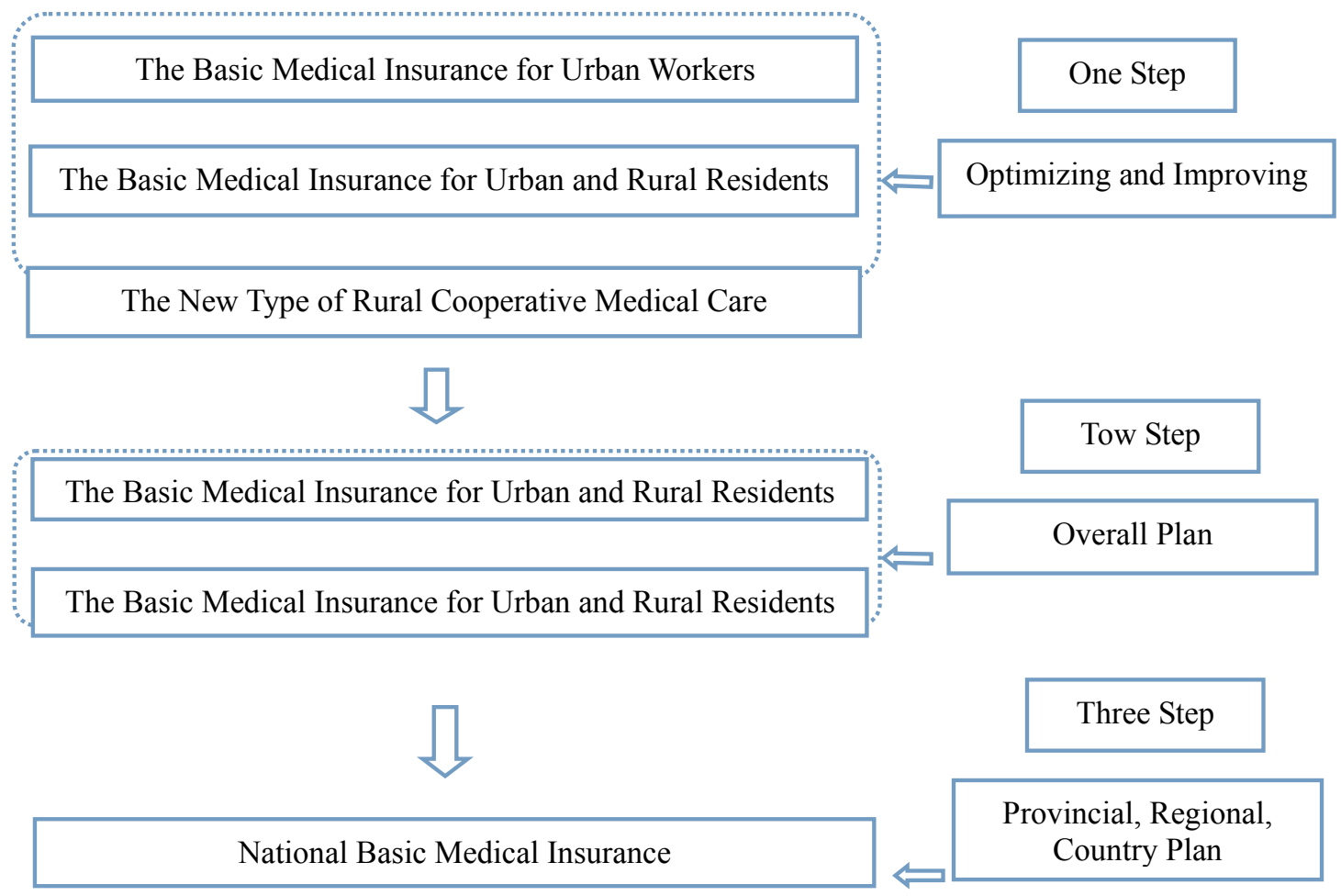

Figure 1. The national basic medical insurance in three steps

As shown in Figure 1, the national basic medical insurance can be divided into three steps. One step is optimizing and improving, which consists of The Basic Medical Insurance for Urban Workers, The Basic Medical Insurance for Urban and Rural Residents and The New Type of Rural Cooperative Medical Care. Tow step is overall plan, which 
consists of The Basic Medical Insurance for Urban and Rural Residents and The Basic Medical Insurance for Urban and Rural Residents. And last, three step is provincial, regional, country Plan, which is National Basic Medical Insurance.

\subsection{To Adjust the Distribution of Financial Expenditure Structure and the Proportion of Expenditure}

The government should be in accordance with the requirements of public finance, improve financial allocation structure and change the unreasonable of ratio of fiscal expenditure. The private nature of the field let the market play a leading role, the weakening of government direct management, the function of financial subsidies, mainly invested in public resource allocation. First of all, medical research foundation with large investment, long cycle, low profit and other features, its cost and application of scientific research beneficial result, it is not easy to be reflected through the market exchange, so the government should increase investment, provide a strong support for the medical and health undertakings. Secondly, the government should make a reasonable distribution of medical resources through the demand of medical resources according to the distribution of financial development in various regions, department, avoid some local excessive medical resources, some serious local medical resources shortage. Thirdly, the government should demand of public health, especially to provide a financial subsidy of poverty, improve health resources, improve the low efficiency and poor people cannot benefit from medical insurance.

\subsection{To Enhance Medical Security Public Awareness}

The public spirit is the attitude and behavior to altruistic way concerned with the public interest, in order to strengthen the medical security of public spirit, state and government must be the leading. Start from education, offering the public spirit education in the compulsory education process, through publicity and education mode to promote the national and set up the correct values, government management should train and educate the medical personnel. Therefore, it is must improve about the public health care field from the point of view of value. Take the social justice as the fundamental values of the social security system, which can be constructed from income compensation, compensation and the mutual aid spending. The social organizations and individuals restored in the inferior position, regulating the economic developed areas and poor areas of the gap between the class members, regulating income gap, reducing poverty.

\section{Conclusion}

In the evaluation of medical insurance fairness criteria, countries around the world have attached great importance to the issue of evaluation of medical insurance, the medical insurance operation, efficiency and fairness for more evaluation. Governments have emphasized the protection of basic health care of people, the main characteristics of the medical system is a social, in order to make the medical risk in large populations within the range. Under the background of the New Medical Reform, medical security career gradually shifts to the public interest and emphasis on health care in the public under the condition of efficiency. But, at present our country still has the problems of insufficient public health care field, which are the loss of health care public mental, lack of publicity in health care management process; the health care system unfair has serious challenge on the publicity value. The deep seated causes of loss of medical security publicity have four parts. First, the medical of system security is fragmentation; second, health care management is decentralized; third, unreasonable of distribution structure and proportion of financial investment. To balance the relationship about leading the marketization of medical services efficiency and the fair dominated about the public health service, we put forward some suggestions. First of all, to build a universal health care system; second, adjust the distribution of financial expenditure structure and the proportion of expenditure; third, perfect the medical security of public decision-making mechanism; finally, strengthening national public spirit.

\section{References}

Chen Jie. Framework for Action to Implement the Evaluation of Health System. Chinese Hospital.

He Xiangbing. (2009). Changes in the Value Orientation of Public Policy in Our Country from the Process of Medical Reform. Journal of Inner Mongolia Agricultural University.

Hu Wei. (2010). Performance of Medical Insurance "Public" Drain, Reasons and Countermeasures. Popular Business.

Hu Xiaoyi. (2009). Toward Harmony: China social Security Development in 60 Years. China's Labor and Social Security.

Hu Yinglian. (2006). Regulation and Market: An Empirical Analysis of the Plight of China's Medical and Health System Reform and the Coping Strategies. The Reform of Economic System. 
Liang Hong. (2007). China's Basic Medical Insurance System Reform Analysis. Fudan Journal (Social Sciences Edition).

Sun Qixiang. (2007). Frame Three Pillar of China's Medical Security System Reform of National Medical Insurance. Economic Science.

Wang Changqi. (2011). Analysis on Medical Safeguard Domain Public Outflow Question. Technological Development of Enterprise.

Xinhua News Agency. (2001). CPC Central Committee and the State Council opinions on deepening the reform of the medical and health. Retrieved from http://www.gov.cn/jrzg/2009-04/06/content_1278721.htm

Zhang Lei, \& Wang Haidong. (2008). Public Social Security: Deletion and Prevention. Social Sciences Review. 